\title{
Entre o cuidado e o controle: Reflexões sobre o cuidado em Saúde Mental
}

DOI: https://doi.org/10.5935/1984-9044.20200020

\author{
Juliana R. de P. Antoneli' \& Bruno Ferreira Emerich ${ }^{2}$ - Universidade Estadual de \\ Campinas (UNICAMP)
}

Resumo: Este ensaio nasceu do encontro de um corpo residente com o cotidiano de cuidado de um serviço de Saúde Mental, um Centro de Atenção Psicossocial III. O olhar para a experiência vivida, trazida por Bondía, tornou-se cenário para inúmeras reflexões, afetos, observações e pensamentos que encontraram palavras em forma de texto, em um relato de experiência. Através de uma narrativa fictícia, buscou-se expor e questionar o lugar do profissional de saúde mental que caminha constantemente pela linha tênue entre cuidado e o controle. A partir da discussão da noção de risco em saúde, este ensaio percorre as práticas de tutela e proteção travestidas em cuidado, que ganham corpo nas instituições e nos profissionais de saúde. No encontro com pensamentos de Abílio Costa-Rosa sobre o campo da Atenção Psicossocial, apontou-se um caminho possível de cuidado, precavido e atento aos labirintos da tutela em Saúde Mental.

PALAVRAS-CHAVE: saúde mental; serviços de saúde mental; profissionais de saúde.

\section{Between care and control: Insigths on Mental Health care}

Abstract: This essay was created from the encounter of a resident body with the daily care of a Mental Health service, a Psychosocial Care Center III. The look at the lived experience, brought by Bondia, became the setting for countless reflections, affections, observations and thoughts that found words in text form, in a report of experience. Through a fictitious narrative, we sought to narrate and question the place of the mental health professional who constantly walks the fine line between care and control. Based on the discussion of the notion of health risk, this essay goes through the tutelage and protection practices dressed in care, that gain body in institutions and health personnel. In the encounter with the thoughts of Abílio Costa-Rosa's thoughts on the field of Psychosocial Care, a possible path of care was pointed out, careful and attentive to the labyrinths of the tutelage in Mental Health.

${ }^{1}$ ORCID: https://orcid.org/0000-0001-7471-408X

2 ORCID: http://orcid.org/0000-0001-7246-5809 
KEY WORDS: mental health; mental health services; health personnel.

\section{Introdução}

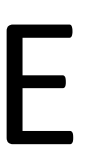

ste ensaio nasceu em forma de texto ao encontrar palavras nos trilhos que conectam a experiência à aprendizagem.

Ele é fruto do movimento, do deslocamento, de um corpo protegido pela teoria da academia, convocado a percorrer a intimidade, o cotidiano, a vida que se passa em um Serviço de Saúde Mental, um Centro de Atenção Psicossocial III (CAPS III). Trata-se das atividades de residente de um programa de formação de trabalhadores que se pretendia teórico e prático, e que, para além dessa dicotomia, propunha um encontro com a experiência, e toda a reflexividade, crítica e afetação que esse conceito carrega.

A condição de residente, passageiro e de passagem, permite um furo na condição de trabalhador, empregado e assalariado, ao se situar como um corpo estrangeiro que habita temporariamente um território físico e existencial do cotidiano do cuidado em Saúde Mental. Ao se localizar em um furo, essa condição permite uma imersão mais lenta, com mais tempo, com menos obrigações e deveres, com outras cobranças, outro chefe, outra fonte pagadora. O tempo é trazido por Bondía como um dos sustentáculos da noção de experiência, na qual, sem ele, no ritmo alucinado do dia a dia, na correria das burocracias, nos corredores das agendas, se torna impossível dar passagem ao que nos passa (Bondía, 2002).

Ao compreender a experiência como algo que nos passa, algo que nos acontece, e não o que se passa, ou o que acontece, Bondía localiza esse conceito para além da compreensão sobre experimento, acontecimento ou conhecimento. A experiência tange o encontro entre algo 
que acontece no mundo e um sujeito disponível a sentir e se afetar, o sujeito da experiência. Este encarna no corpo o acontecimento, ou seja, oferece um lugar de passagem ao acontecido, o qual já não é mais um fato, e sim uma experiência vivida (Bondía, 2002).

Segundo esse autor, o sujeito da experiência é sofredor, padecente, receptivo, aceitante, interpelado, submetido. Ele é sujo e vivido, se expõe, coloca os pés na lama, e se permite enlamear-se (Bondía, 2002). A experiência, como algo que forma e transforma, encontra aqui palavras em cadência de um texto, em um relato de experiência, para levantar questões importantes, urgentes e cotidianas de um serviço que se pretende substitutivo aos manicômios.

O cuidado no CAPS exerce uma importância sine qua non ao novo modelo de atenção pensado e proposto pelo Movimento de Reforma Psiquiátrica. Segundo Amarante (2003), a Reforma é um processo social complexo, que envolve muitas dimensões, teóricasconceituais, jurídico-político, técnico- assistencial e sociocultural. Esse movimento (Yasui, 1999) foi iniciado por trabalhadores, familiares e usuários indignados com os diversos tipos de violência dentro dos manicômios na década de 1980, e teve como ápice a criação da lei 10.216. Sendo o serviço em questão um componente da dimensão técnico-assistencial da Reforma Psiquiátrica, como diz Yasui (1999), ele representa um novo cuidado, uma nova maneira de se fazer, diferente da lógica manicomial.

Dessa forma, o cuidado em saúde mental desloca a centralidade do Hospital Psiquiátrico, no tratamento de pessoas em sofrimento psíquico, para um cuidado em rede, composto por diversos serviços de base comunitária no SUS. A ideia de rede, de Rede de Atenção Psicossocial, conhecida como RAPS (Ministério da Sáude, 2011), busca superar o paradigma Hospitalocêntrico e Medicalizador dos manicômios, o qual não pode ser comemorado como superado com a derrubada concreta de seus muros. Tratando-se de um paradigma, a superação dele se dá todos os dias, inclusive nos serviços já 
comunitários. Não como um objetivo alcançável, apalpável, mas como um cenário que necessita estar no pano de fundo e horizonte de nossas práticas, precavendo-nos dos abismos que residem entre o cuidado e controle.

Assim como a noção de experiência oferece um risco, um perigo relacionado a sua travessia corajosa do sentir, a clínica de um CAPS III também se mostrou, para mim, um convite à reflexão sobre como a noção de risco da vida viva dos sujeitos que cuidamos permeia as nossas práticas, e podem chegar a ditar nossa clínica, amarrando nossas mãos que cuidam à noção de cuidado como controle, como gestão de riscos.

Desse modo, iniciamos aqui essas reflexões, críticas e pensamentos oriundos dos pés enlameados, dos sentimentos atravessados, dos afetos escutados, dos silêncios observados, das palavras vomitadas e das engolidas que fizeram parte dessa travessia na Saúde Mental. Foi construída uma narrativa fictícia, que será disparada na sequência. Trata-se de uma bricolagem de cenas reais, com afetos intensos e reflexões teóricas sobre os caminhos tortuosos do cuidado em Saúde Mental.

\section{Narrativa: 0 risco do cuidado e o cuidado do risco}

O sol do meio dia arde lá fora, e você sua frio ali dentro. Em uma sala, em volta de uma mesa, com inúmeras pessoas em roda, o relógio diz que a passagem de plantão começou. Não tarda muito para o inquérito estar posto na mesa, assim como um bolo de chocolate que ninguém levou. Diferente do doce chocolate, a amarga pergunta surge: Quem é o Profissional de Referência do fulano? Em poucos segundos, sem ao menos receber a resposta, já se pode identificar o pobre coitado. Aquele que está acuado esperando um buraco se abrir no chão. 
Infelizmente, ninguém pergunta quem é o profissional de referência para oferecer um pedaço de bolo de chocolate, mas sim, para informar que algo de ruim aconteceu com seu usuário de referência. Aliás, acontecido esse que você já deveria estar sabendo. Afinal, o que você não fez para que isso acontecesse?

Antes fosse um bolo de chocolate na mesa, mas é seu trabalho, você inteiro, inclusive seus órgãos de profissional de referência sendo dissecados ali. Externamente, você vê seus próprios pedaços sendo examinados. Pegam o seu fígado e perguntam: Mas porque você não fez uma visita domiciliar antes? Encontram seu pulmão e indagam: Como é que você não o levou em um Centro de Saúde? E ali embaixo das costelas, pegam seu coração na mão e dizem: Como é que isso foi acontecer?

Com seus órgãos expostos e seu trabalho em cheque, a culpa brota junto ao seu suor frio. E logo surge a segunda amarga pergunta, essa feita, agora, a partir da luta interna entre seus próprios órgãos que tentam se acomodar novamente em seu corpo: Como é que eu deixei isso acontecer? Nada que você responda será suficiente para tantas perguntas inférteis feitas tarde demais. Afinal, a vida cabe na clínica? Todas as dimensões da vida de um usuário cabem em um serviço de saúde? O papel de super-herói salvador de vidas cabe no papel de profissional de referência? Quem está em risco? O usuário ou o profissional que tem seus órgãos, ou melhor, seu trabalho exposto e indagado?

Com certeza os dois. O usuário por estar na vida e correr o risco de estar vivo, e nós, profissionais, que somos colocados no lugar de culpados da vida viva, que muitas vezes vai mal, de quem cuidamos. Colocar o profissional no lugar de responsável por todos os impasses, deslizes, tropeços e tropicões da vida de quem se cuida é fazer da referência um lugar muito doloroso de se habitar. Um lugar insuficiente, pois jamais controlaremos as inúmeras ciladas que a vida viva nos coloca, muito menos a da vida alheia.

Afinal, para controlar todas as dimensões da vida se faz mais fácil colocar todos 
usuários dentro de manicômios que, em nome da proteção, tanto matou e tanto mata. Manicômio não mata de acidente de carro, nem de overdose, tampouco de afogamento em mar, porque só morre assim quem está livre. Mas, em nome da proteção que controla, mata de frio, mata de negligência, mata de esquecimento e mata tudo que há de vivo e subjetivo. Falo da morte pois talvez seja a única certeza que temos na vida, e nem por isso é algo que se controla.

E é de controle que me proponho a falar. Do controle feito através da gestão de riscos.

Pensemos na palavra risco.

Segundo o dicionário Aurélio, risco está associado a palavra perigo (Ferreira, 1995). Já para Epidemiologia (Castiel, Guilam e Ferreira, 2010), o verbete risco está relacionado à probabilidade de ocorrência de um evento mórbido ou fatal. A palavra, em sua origem do espanhol, está relacionada a grande penhasco, e se relacionava aos perigos ligados às grandes navegações, assim indicava tanto a ideia de perigo como a de possibilidade de ocorrência de algum grande evento. Dessa maneira, o risco está ligado a probabilidade. Sendo uma probabilidade, ele pertence a uma dimensão virtual, no sentido de algo que não aparece explicitamente, mas como potencialidade, em latência, passível de se realizar (Castiel, Guilam e Ferreira, 2010).

O conceito de risco é profundamente estudado em algumas disciplinas, como engenharia, ciências econômicas, ciências sociais e epidemiologia. No caso desta última, a epidemiologia, sendo muito utilizada como análises populacionais para se pensar em ações de promoção em saúde. Nesse âmbito, fatores de riscos são quantificáveis e calculáveis pela racionalidade científica, estabelecendo, assim, uma relação lógica entre doença e suas causas (Castiel, Guilam e Ferreira, 2010).

Segundo Castiel e Diaz (2007), em seu livro Saúde Persecutória, ao operar com a categoria risco estamos entrando em um campo probabilístico futurológico. Ao mesmo tempo que parte do princípio de uma racionalidade científica, no caso da epidemiologia, não nos dá certeza 
absoluta de que o risco venha se tornar fato. Isso nos permite abstrações e proliferações imaginárias, propícias a cogitações, criando assim um discurso que, pela falta de certeza e consistência, não proporciona segurança e, muito menos, tranquilidade (Castiel e Diaz, 2007).

Ao longo da minha curta trajetória na Saúde Mental, fui recolhendo o que era considerado como um risco para os usuários, e a conclusão a que cheguei é que, diferentemente da epidemiologia, os riscos em saúde mental, em um tratamento longitudinal, são pouco quantificáveis, pois dizem de uma singularidade, como, por exemplo: risco de não tomar a medicação, risco de fuga, risco de não se alimentar bem, risco de ir morar sozinho, risco de gastar todo o salário em cinco dias, risco de se drogar, risco de engravidar, dentre outros. Notase que esses riscos são muitos distintos dos riscos relacionados à promoção de saúde, pois os riscos em saúde mental são subjetivos, não dizem de uma análise populacional, e sim advêm de questões cotidianas, conflitos do dia a dia, impasses da vida de cada sujeito.
Se pensarmos os riscos como uma probabilidade de acontecimentos, a gestão dos riscos toma o lugar da vidência, onde o profissional de saúde, a referência, se torna um vidente que prevê o futuro e que intervém no presente para que nada de ruim aconteça. Tratando-se dos riscos em saúde mental, é quase como achar que é possível manejar as curvas imprevistas da vida, em uma rodovia, em dia tempestade, com um patinete. Lugar complicado este, onde o cuidado se torna controle, as evidências se tornam vidências, e o risco um ponto de estagnação. Ao se ter em mente que nada de ruim possa acontecer com o outro, caímos em uma cilada, pois a vida é hora ruim, hora boa, e hora ruim de novo... a vida transborda. Além disso não podemos esquecer do conteúdo moral em que essa análise é baseada, onde o ruim muitas vezes é o ilegal; e também a variação do que é considerado por cada um como certo e errado, saudável e danoso (Castiel e Diaz, 2007).

Dessa maneira, o risco entra como uma biopolítica de controle, a qual exerce um poder sobre os fenômenos globais para 
assegurar e otimizar a vida, o que Foucault (2005) vai chamar de uma regulamentação sobre a vida. A biopolítica, segundo Foucault (2005, p.294), “obtém estados de equilíbrio, regularidade, em resumo, de levar em conta a vida, os processos biológicos do homem-espécie e de assegurar sobre eles não uma disciplina, mas uma regulamentação."

Dessa maneira, a intervenção é na maneira de viver, no "como" se dá a vida, fundamentado no argumento de aumentar a vida, controlar seus acidentes, suas eventualidades, suas deficiências. Assim, a ideia de saúde fica restrita à noção de segurança, e a vida fica blindada de riscos vinculados à ideia de prazeres perigosos. Então se vê a vida prolongada e submetida ao aniquilamento dos riscos, porque muitas vezes a morte não se dá de forma biológica, mas sim subjetiva, uma morte em vida (Foucault, 2005).

A questão delicada é como podemos pensar nos riscos, sem negarmos a sua existência, e agir de maneira alinhada a uma ética do cuidado e não do controle?
Pois, afinal, os riscos existem, e muitas vezes somos convocados a intervir; mas como não se exceder neste cuidado que está ao lado do controle, da tutela, da proteção?

Costa-Rosa (2011), ao retornar a Lacan, traz à tona a ética do cuidar-se ao pensar em uma ética para Atenção Psicossocial. Ele nos alerta para a possibilidade de o profissional de saúde cair no lugar do mestre, o qual possui um saber a ser passado para o sujeito, considerado como um objeto a ser transformado, melhorado e guiado pela ação de alguém mais sábio. O lugar do mestre é o da tutela, controle e proteção (Costa-Rosa, 2011).

Uma das saídas para esse impasse indica a ética do cuidar-se, diferenciando-a da ética do cuidado. Para que a ética do cuidar-se seja possível, é necessário que exista vínculo e escuta. O vínculo, aqui, visto como possibilidade transferencial de enunciação subjetiva do usuário, apoiada em uma escuta posicionada no lugar do intercessor, e não do mestre. Este, capaz de promover ações de emancipação e protagonismo, pois não 
se limita a uma resposta de como o usuário deve fazer, e sim a um reposicionamento, processo em que novos sentidos aos impasses serão construídos pelo sujeito, o qual encontrará, por si, novos caminhos. Além disso, cabe ao profissional de saúde mostrar as possíveis consequências dos novos caminhos, para que as direções tomadas sejam conscientes. Assim, pertence ao usuário a responsabilidade sobre suas decisões e desejos. E o profissional de saúde atua como um secretário que ajuda a assessorar a vida do usuário em seus impasses, estando a seu lado, e não conduzindo-o. Caminhando juntos, e não carregando-o no colo (Costa-Rosa, 2011).

Diferente da clínica da gestão dos riscos, onde se almejam solos seguros, na clínica do desejo alinhada à ética do cuidar-se, o sujeito em sofrimento constrói suas decisões e escolhas de forma coerente ao seu desejo. O que não nos garante que será um caminho ideal, nem seguro, nem tranquilo, nem previsível, tampouco fácil, nem pra nós profissionais expostos em cima da mesa, nem para os usuários. Contudo nos garante que a decisão foi tomada pelo sujeito, a qual condiz com a sua vida e as suas possibilidades de existência. Desse modo, seu protagonismo está assegurado, seu desejo respeitado, e sua responsabilidade reconhecida. Assim, cabe ao sujeito decidir e assumir os riscos que irá correr, precavido de suas consequências, pois toda vida repleta de desejos e sentidos possui riscos.

Gostaria de lembrar que obviamente em situações extremas teremos que intervir, internar, medicar, ou conter. Manter-nos atentos para que essa análise se apoie em riscos reais, frutos de um cálculo clínico, e não de uma escuta baseada em riscos virtuais, pode nos manter precavidos de tomar decisões atravessadas por proliferações imaginárias e medos. Desse modo, tratase de colocar a contradição na mesa, e não negar a responsabilidade que temos com uma vida que se anuncia perigosa para si ou para os outros. Analisar os riscos que uma vida corre é assumir a contradição que existe entre a autonomia das vidas que cuidamos e o cuidado que exercemos 
Avaliar até onde nossas mãos que cuidam conseguem chegar também é assumir em nós a ilusão onipotente de cuidado, e é também reconhecer em nós a responsabilidade que temos e, a partir disso, inventar maneiras de cuidar que, ao mesmo tempo que se responsabilizam, também deixam ser. Os riscos reais nascem de vidas vivas, já os virtuais nascem do medo da vida viva. Entender que esse medo também existe em nós, profissionais vivos, em volta de

\section{Considerações finais}

Este ensaio percorreu os corredores dos territórios da saúde mental, e permitiuse afetar pelas vidas vivas que cuidam e pelas que se deixam ser cuidadas, a fim de pensar maneiras e caminhos de se dispor ao cuidado. E assim se propôs a discutir o risco como um ponto importante ao olhar para a linha tênue que separa o controle do cuidado.

Aponta-se que, a partir da escuta, do vínculo, e de uma análise de riscos coerente e baseada em um cálculo clínico, é possível estar ao lado do sujeito uma mesa, é localizar o que sentimos, dar lugar ao que aparece, e pensar, dentro de nossas contradições, cuidados vivos para vidas vivas.

Afinal, reduzir o cuidado de uma vida ao cuidado do risco é, de certa forma, não dar lugar ao risco que corremos ao cuidar, é deixar a contradição embaixo da mesa e permitir que essa amarra negada conduza nossas mãos que cuidam.

protagonista de seu desejo e caminhar com ele nas veredas da vida, as quais não deixam de ser demasiadas perigosas, mas feitas de riscos reais, e não de antecipação de riscos virtuais.

É ter em mente que o cuidado nos coloca à beira de um risco, ou melhor, de um rio, pronto para o mergulho. A gestão dos riscos grita: "Não pule, muito perigoso!" A clínica do desejo não diz nada, ela averigua o território e sugere: "ali naquele canto dá para pular". E assim um risco virtual se torna uma evidência real 
que mostra que não é o pulo a questão, e sim o reconhecimento das profundezas, o qual dá chance ao salto, mas um salto calculado.

Dessa maneira, saímos do lugar do agente salvador, que deve salvar antes mesmo do pulo. Obviamente seguiremos sendo questionados sobre nossas condutas e sobre o que deixamos de fazer, em pleno meio dia, em volta de uma mesa. Mas penso que se gastássemos a energia que gastamos dissecando os órgãos do profissional referência com a dissecação do desejo de nossos usuários - e de suas profundezas

-, tornaríamos nossos dias mais doces e menos amargos. Cuidar em liberdade é difícil, mas mais difícil ainda é quebrar os nossos muros internos e nossa ânsia por proteger. É necessário lembrar que não adianta lapidar a vida para caber na caixinha da clínica, pois corremos o risco de deixar tudo muito pequeno, principalmente o desejo que resta em nossos usuários. Afinal, como diz esta frase, que tem a autoria atribuída a vários autores, e de data desconhecida: "Um navio está seguro no porto, mas não é para isso que os navios foram feitos"

\section{Referências}

Amarante, P. (2003). A (clínica) e a Reforma Psiquiátrica. Editora Nau.

Bondía, J. L. (2002). Notas sobre a experiência e o saber de experiência. Revista Brasileira de Educação, 19(20-28). https://doi.org/10.1590/s141324782002000100003

BRASIL. (2011). Ministério da Saude. Portaria $n^{\circ}$ 3.088/GM, de 30 de dezembro de 2011. 
ENTRE O CUIDADO E O CONTROLE: REFLEXÕES SOBRE O CUIDADO EM SAÚDE MENTAL

http://bvsms.saude.gov.br/bvs/saudelegis/gm/2011/prt3088_23_12_2011_rep. html

Castiel, L.D.; Guilam, M.C. \& Ferreira, M. S. (2010). Correndo o Risco: uma introdução aos riscos em saúde. Rio de Janeiro: Fio Cruz.

Castiel L.D.; Diaz C.A.D. (2007). A saúde persecutória: os limites da responsabilidade. Rio de Janeiro: Fio Cruz.

Costa-Rosa, A. (2011). Ética e Clínica na Atenção Psicossocial: Contribuições da psicanálise de Freud e Lacan. Saude e Sociedade, 20(3), 743-757.

https://doi.org/10.1590/S0104-12902011000300018

Foucault, M. (2005). Em defesa da sociedade. In Em defesa da sociedade. São Paulo: Martins Fontes.

Yasui, S. (1999). A Construção da Reforma Pisquiátrica e o seu contexto (Dissetração de Mestrado). Universidade Julio de Mesquita (UNESP), Assis.

Recebido em: 08/08/2020 Aprovado em: $15 / 12 / 2020$ 